\title{
Numerical analysis of the influence of maximum residual thermal stresses on the intensity factor between the matrix and particle interfaces in metal matrix composite
}

\author{
Nehari Taieb \\ Smart Structures Laboratory (SSL) University Centre of Ain Témouchent-Belhadj Bouchaib, Po Box 284,46000, Algeria. \\ nehari1976@gmail.com, https://orcid.org/0000-0002-4525-0105 \\ Bahram Kaddour, Nehari Driss \\ University Centre of Ain Témouchent-Belhadj Bouchaib, Department of Mechanical Engineering, Po Box 284,46000, Algeria, \\ Kadero_7@hotmail.com, bttps://orcid.org/0000-0002-2338-1438 \\ Smart Structures Laboratory (SSL) University Centre of Ain Témouchent-Belhadj Bouchaib, Po Box 284,46000, Algeria. \\ nehari_dr@yahoo.fr, bttps://orcid.org/0000-0003-2524-424X
}

Marni Sandid Abdelfatah

Smart Structures Laboratory (SSL) University Centre of Ain Témouchent-Belhadj Bouchaib, Po Box 284,46000, Algeria. abdelfatahsandid@hotmail.com, https://orcid.org/0000-0001-7592-967

\begin{abstract}
A critical problem in the application of metal matrix composites is the presence of high residual thermal stresses induced during the development process. These thermally induced stresses are generally detrimental to the service life of this type of composite. This article discusses the influence of maximum residual stresses on the intensity factor. The results interpreted in terms of damage, allowed us to identify the risk zones; characterized by a significant level of maximum residual stresses $\left(\mathrm{S}_{11 \mathrm{Max}}, \mathrm{S}_{22 \mathrm{Max}}\right.$, $\mathrm{S}_{33 \mathrm{Max}}$ ), namely the particle/Matrix interface.

The results also show that the loading conditions and the inter-distance between matrix and particle with two interfacial cracks have an important effect on max residual stresses and stress intensity factors.
\end{abstract}

KEYWORDS. Maximum residual stresses; Crack; intensity factor.

\section{open ACCESS}

Citation: Nehari, T., Bahram, K., Nehari, D., Marni Sandid, A., Numerical study of the analysis influences the maximum residual thermal stresses on the intensity factor between the matrix/particle interfaces in CMM, Frattura ed Integrità Strutturale, 54 (2020) $275-281$.

Received: 08.05.2020

Accepted: 05.09 .2020

Published: 01.10 .2020

Copyright: (c) 2020 This is an open access article under the terms of the CC-BY 4.0, which permits unrestricted use, distribution, and reproduction in any medium, provided the original author and source are credited.

\section{INTRODUCTION}

oday, Metal Matrix Composite materials (MMC) are highly concerned materials in engineering applications mainly because of their mechanical properties and characteristics in general, these materials often have very high specific rigidity, strength and low density. 
However, during the planning of the composites at relatively high temperatures, residual stresses arise during the process of cooling these temperatures to room temperature. They are essentially due to the difference in the coefficients of thermal expansion between the particle and the matrix. A gap that is too large delicate the adhesion between these two constituents and consequently favors the initiation and propagation of fatigue microcracks.

Fatigue microcracks can start in one of these two constituents and their propagation leads to the ruin of the composite. Interfacial cracks, responsible for disbanding, may be due either to poor mechanical bonding or to the existence of internal shear stresses at the reinforcement-matrix interface that are too high.

In this work, we study the variation of the stress intensity factor (SIF) in the opening modes (mode I) and in the shearing modes (modes II and III). Under the effect of the residual stress, a matrix crack, oriented, relative to the axis of the fibre, propagates at the heart of the matrix, in mixed modes I, II and III. Such a crack crosses the fibre-matrix interface by shearing of its lips (modes II and III). The instability of the crack increases with the increment in the temperature of the elaboration of the composites. Under the effect of the tension of putting into service of the composite, the crack of the matrix develops in pure mode I and penetrates into the fibre by opening its lips. The propagation kinetics are strongly slowed when its front approaches very proximity to the fibre-matrix interface, and then develops rapidly in the fibre. This behaviour is all more accentuated as these tensions are stronger [1].

Using a simple cubic cell model with square reinforcement forms was developed to study its effect on the mechanical properties of MMC. The objective is to calculate stress intensity factors $K_{I}$ and $K_{I I}$ for cracks in the matrix and particles. The results also show that the loading conditions and the inter-distance between two particles with two inter-facial cracks have a significant effect on the stress intensity factors $K_{I}$ and $K_{I I}, K_{I I I}$ [2].

In this study, the analysis of the residual thermal stresses of boron fibre reinforced epoxy matrix composite and the effect of fibre inter-distance. The strongest constraints are located in the immediate vicinity of the interface. Its state and level, radial stresses promote adhesion between the matrix and the fibre. The increase in the fibre fraction implies a reduction of the internal stresses of the reinforcing material and its increase in the matrix. The interaction of two fibres, plays an important role on the internal plane: in the matrix if low inter-distance implies an amplification of longitudinal stresses of about four times and circumferential stresses of thirty times, and also leads a fall of the internal longitudinal stress in reinforcing material. A reduction of the fibre-fibre distance implies a decrease in the amplitude of the induced fibre stress circumference [3].

In the 1960s, Hashin and Shmuel [4] developed analytical models that predict the elastic thermomechanical properties of perfect multi-phase materials: cohesive and free of damage. However, most of these materials have numerous micro-cracks resulting from the thermal expansion disagreement between the phases involved. These micro-cracks, also called damage, result from the thermal history, usually complex, of the material studied. These damages strongly influence the thermomechanical macroscopic properties of these materials and can have a strong influence on their service life.

The present work concerns the numerical study by the finite element method of residual stresses in a metal matrix composite reinforced by spherical particles $(\mathrm{SiC})$. These composites are elaborate at relatively high temperatures. Their cooling (from the working temperature to the ambient temperature), leads to the creation of residual stresses, the distribution and amplitude of which are closely linked to the gap between the physical and mechanical properties of the matrix and the particle. The first part is to highlight the effect of the crack inter-distance on the maximum residual stresses (in the matrix and particle) and the second part presents the effect of crack size on the intensity factors of constraint $K_{I}$, $K_{I I}$, and $K_{I I I}$.

\section{MODEL USED}

A three-dimensional analysis by the finite element method has been developed for the simulation of maximum residual stresses in the $\mathrm{Al} / \mathrm{SiC}$ couple. The mechanical behaviour of the metal analysed is purely elastic. Fig. 1 shows the model of the structure composed of a matrix-particle assembly and the meshing used for the analysis of the distribution and the level of the stresses in the vicinity close to the interface. Due to the symmetry of the studied structure, only half of it has been considered and modelled (to reduce the calculation time). With a width crack a $=10 \mu \mathrm{m}$, and inter-distance $\mathrm{d}=0.1 \mu \mathrm{m}$. The calculation code used for this analysis is ABAQUS (6.11) Standard, using general purpose C3D4 (a 4-node linear tetrahedral type element, 1 integration point, uses a linear shape function; this is first order element of stress / displacement analysis; the number of elements is 52750). This element provides precise results only in general cases with a very fine mesh [5]. The thermal cycle used for the calculation consists of heating at a given high temperature up to $600^{\circ} \mathrm{C}$ followed by cooling to the ambient temperature of $20^{\circ} \mathrm{C}$ at a constant velocity. 
The internal stresses are a function not only of the deviation between the coefficients of thermal expansion of the matrix and the particle, of the deviation between the temperature at which the thermoplastic deformation disappears and the temperature at which it is formed, but also the modulus of elasticity and Poisson coefficient of the two constituents (particle and matrix):

$$
\sigma_{\mathrm{R}}=\frac{\left(\alpha_{m}-\alpha_{f}\right)\left(T-T_{0}\right)}{\frac{1+v_{m}}{2 E_{m}}+\frac{1-2 v_{f}}{E_{f}}}
$$

The effect of internal stresses on crack behaviour is analyzed in terms of variation of the stress intensity factor in opening modes (mode I) and shear modes (modes II and III).
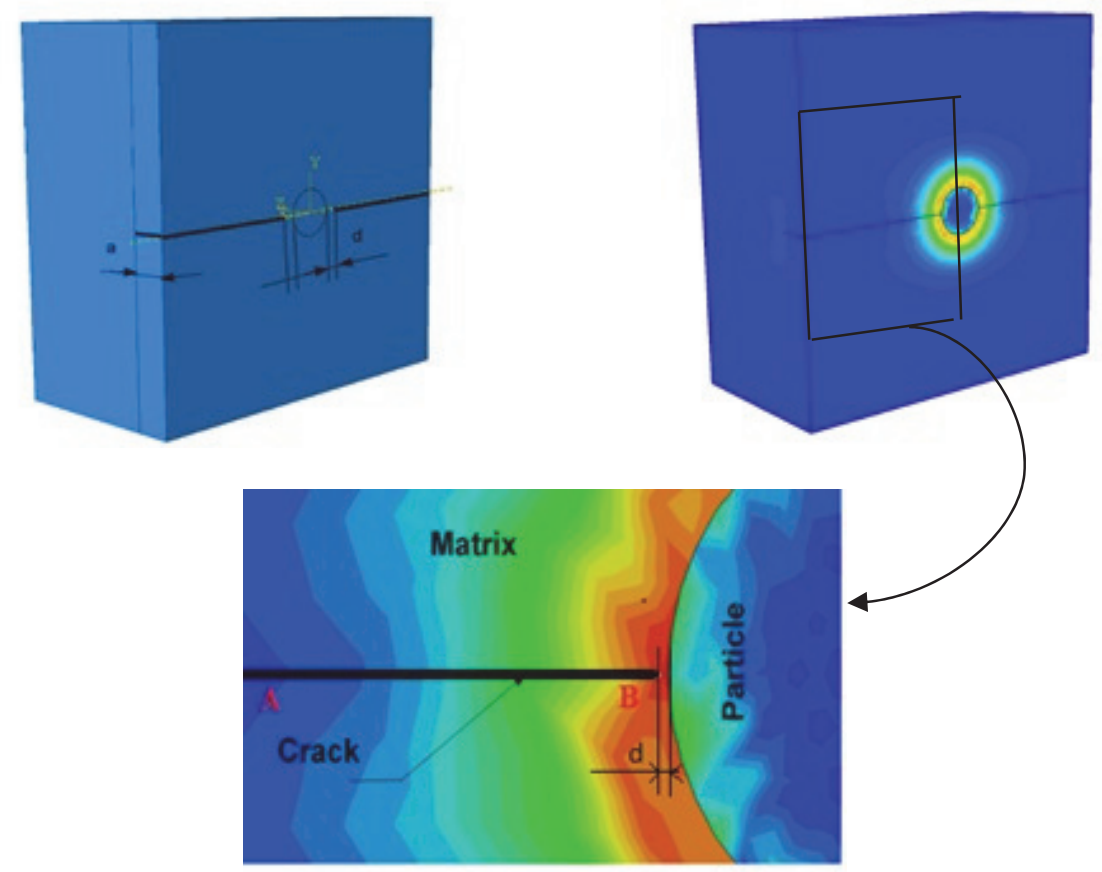

Figure 1: Distribution of the residual stress of Von Mises $\mathrm{d}=0.1 \mu \mathrm{m}, \mathrm{a}=10 \mu \mathrm{m}, \Delta \mathrm{T}=300^{\circ} \mathrm{C}$

\begin{tabular}{ccc}
\hline Property & Matrix & Particle \\
$\begin{array}{c}\text { Material } \\
\text { coefficient of thermal } \\
\text { expansion }\left(\mathrm{K}^{-1}\right)\end{array}$ & Aluminum & $\mathrm{SiC}$ \\
Modulus of elasticity & $23.4 \mathrm{E}^{-6}$ & $5.12 \mathrm{E}^{-6}$ \\
$(\mathrm{GPa})$ & 70 & 408 \\
Poisson ratio & 0.3 & 0.2 \\
Yield strength $\mathrm{MPa}$ & 275 & 0 \\
\hline
\end{tabular}

Table 1: Mechanical and physical properties of the Materials used in the simulation.

\section{RESULTS AND DISCUSSION}

he results of the numerical simulations at for purpose study the influence of temperature variation and inter-distance (d) between crack and particle on maximum residual stresses and stress intensity factors.

The numerical code "Abaqus 6.11" was valid by comparing the numerical results with those collected in the literature $[1,2]$. The Fig. 5 show the stress intensity factor values $K_{I}, K_{I I}, K_{I I I}$. Which attest to the good agreement of the results with a small gap. 


\section{Effect of crack penetration on maximum stresses}

The residual stresses on the surface of the matrix-particle junction are shown in Fig.2, which represents the Von Mises stress distribution for the case $\left(a=10 \mu \mathrm{m}, \mathrm{d}=0.1 \mu \mathrm{m}\right.$ and $\left.\mathrm{T}=300^{\circ} \mathrm{C}\right)$. This stress is very important at the crack tip when propagating to particle; it is of the order of $286 \mathrm{MPa}$. In the same direction, the effect of the very close crack of the particle on the stress levels of Von Mises at the interface of the matrix and particle expressed in Fig. 2 which also shows a high stress concentration approximately the crack tip and which extends to particle. It is should be noted that the maximum stresses in the particle are at the bottom while those of the matrix are close at the bottom; this is mainly due to the interaction effect and difference of the mechanical properties of the materials.
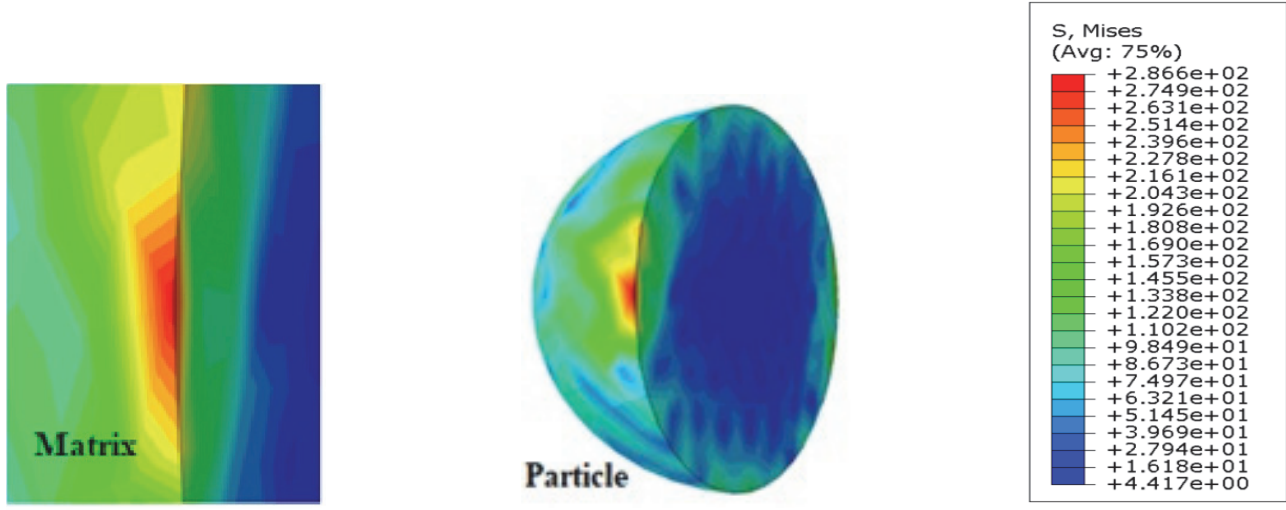

Figure 2: Crack-particle interaction $\left(a=10 \mu \mathrm{m}, \mathrm{d}=0.1 \mu \mathrm{m}, \Delta \mathrm{T}=300^{\circ} \mathrm{C}\right)$.

\section{Level of maximum residual thermal stresses}

Residual thermal stresses in a composite subjected to a thermomechanical load such as three-dimensional. The distribution of the maximum residual stresses relative to the principal axes of a well-defined reference point, obtained by the finite element method is illustrated in the Figs. 3 and 4 the distribution of maximum residual stresses in the matrix and particle can be seen from these figures.

Analysis of the distribution of maximum residual stresses revealed that they are more intense in the centre of the junction than at the edge. In addition, the interface can be easily identified as the interface most affected by these constraints. For a best of this illustration of these results, the distribution of maximum stresses reported for the zones of the matrix to the particle, according to the two positions.

Fig. 3 reports the variation in maximum residual stress as a function of the crack-particle inter-distance. We notice that following this configuration, the particle is in compression and the matrix in tension. This behavior is due to the velocity of cooling which is more in the matrix compared to the particle $\left(\alpha_{\text {matrix }}>\alpha_{\text {fibre }}\right)$. The interface on the matrix subjected to high circumferential tension, mainly at the edge. In combination with compaction defects, this stress usually elicits radial cracks in the matrix, which can significantly affect the material. On the other side in the particle, this constraint is more intense than in the matrix, its amplitude is the same level as that radial, and remains almost invariable what that whether of the interface-particle distance. The state of the stresses and their distribution in the particle, the analysis shows that the composite material behaves like a homogeneous material. The state of the stresses and their distribution in the particle, the analysis shows that the composite material behaves like a homogeneous material.

Figs. (3.a), (3.b), illustrate the variation of the maximum residual stresses recorded in the particle ( $\mathrm{SiC}$ ), the analysis of these figures shows clearly that a proportionality between the maximum residual stress decrease, and the temperature. In addition, there is an acceleration in the level of these maximum residual stresses by exceeding inter-distance $(\mathrm{d}=0.4 \mu \mathrm{m})$.

For Fig. (3.c) illustrates the variation of the maximum residual stresses according to the direction $\mathrm{S}_{33 \mathrm{Max}}$, we note that the maximum stresses increase progressively sensibly afield from the inter-distance that is to say $(\mathrm{d}=0.4 \mu \mathrm{m})$ contrary to the centre. This observation explained by a low energy characterizing this zone.

Fig. 4 shows the variation of the maximum residual stresses generated in the three directions $S_{11 \max }, S_{22 \max }, S_{33 \max }$ of the matrix as a function of the crack width. This figure shows that the residual stresses intensively localized at the matrix interface. The level of these constraints progressively increases us near of the link interface. In the vicinity very near of the interface, these residual stresses reach their maximum intensity. The maximum residual stress according to $\mathrm{S}_{11 \mathrm{Max}}$ of about three times $\mathrm{S}_{33 \mathrm{Max}}$. 

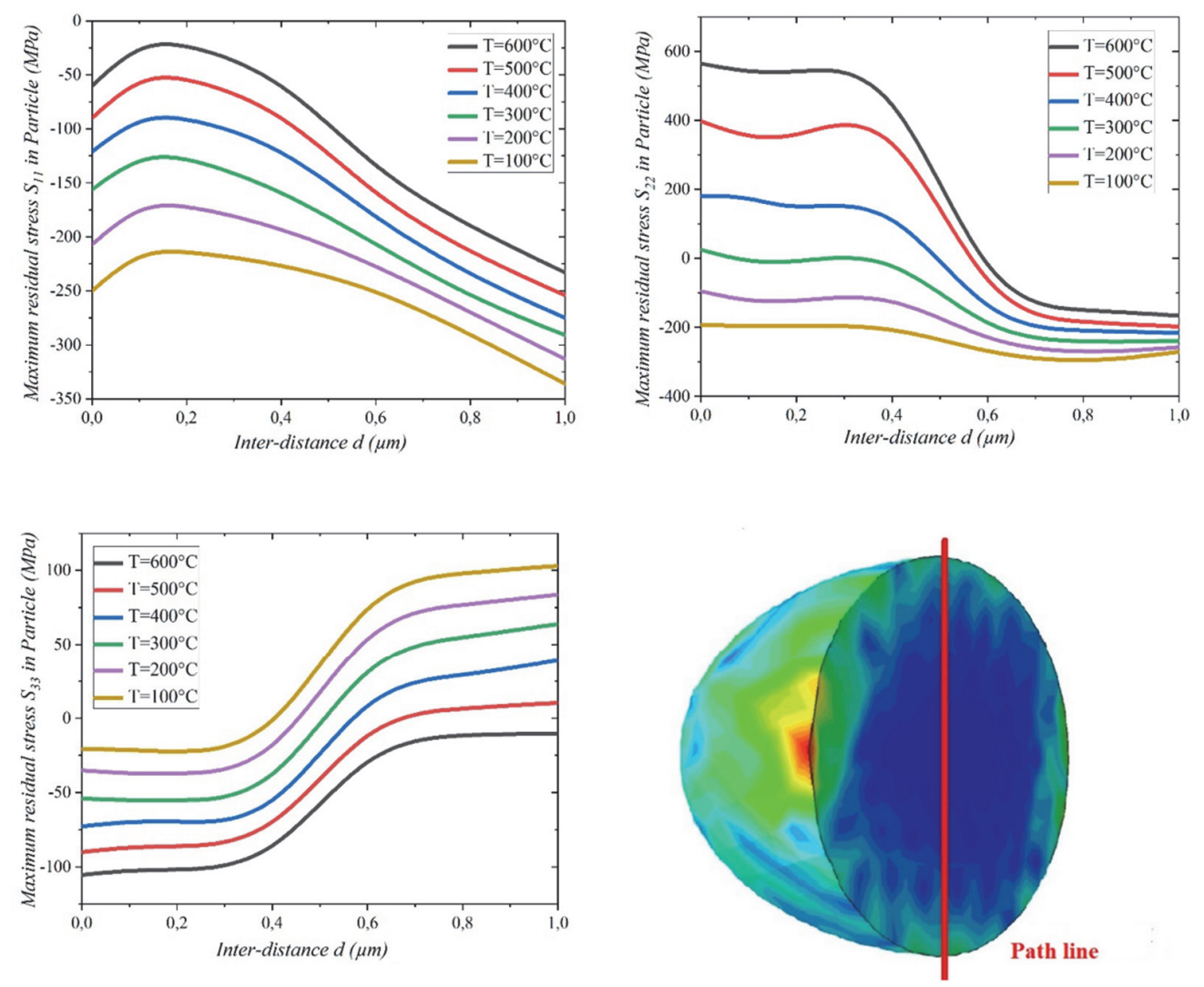

Figure 3: Level of maximal residual stress $\mathrm{S}_{11 \mathrm{Max}}, \mathrm{S}_{22 \mathrm{Max}}, \mathrm{S}_{33 \mathrm{Max}}$ in particle following the path line $(\mathrm{a}=10 \mu \mathrm{m}, \mathrm{d}=0.1 \mu \mathrm{m})$.
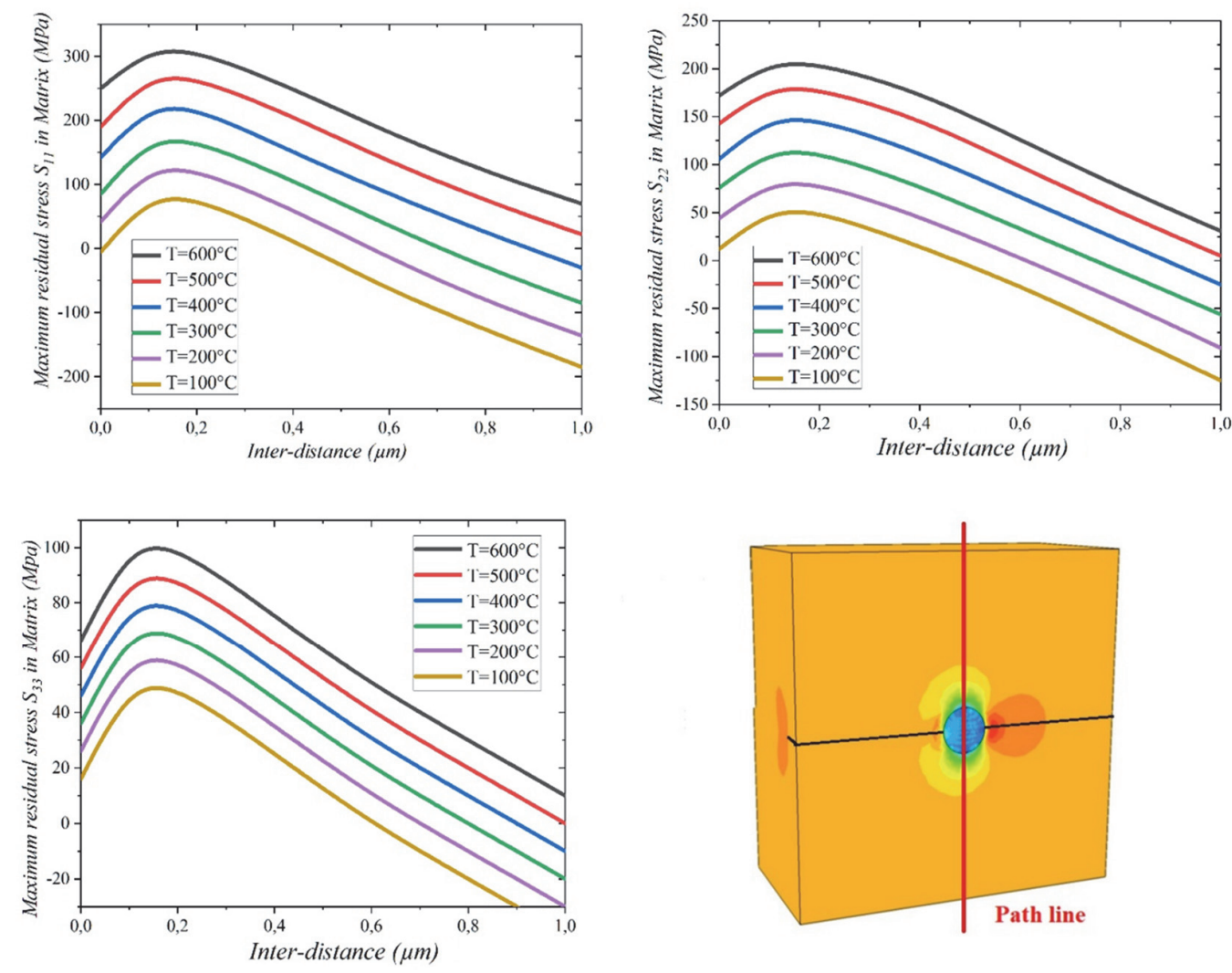

Figure 4: Level of maximal residual stress $\mathrm{S}_{11 \mathrm{Max}}, \mathrm{S}_{22 \mathrm{Max}}, \mathrm{S}_{33 \mathrm{Max}}$ in matrix following the path line $(\mathrm{a}=10 \mu \mathrm{m}, \mathrm{d}=0.1 \mu \mathrm{m})$. 


\section{The effect of residual stresses on the intensity factor}

The results obtained in this part of the work show that under the effect of residual stress, a crack, initiated in the matrix, propagates in pure mode I when its front is located relatively far from the interface with the particle and in mixed mode I, II and III when its front approaches this interface.

Fig. $5 \mathrm{a}$ shows that the residual tensile stresses in the matrix act as crack opening stresses. In Mode I, the stress intensity factor values increase when the crack size passes through the interface at $(\mathrm{d}=0.1 \mu \mathrm{m})$ and temperature. In the particle, the residual stresses are in the form of compression stresses that act as the closing stresses of the crack.

In mode II, the crack tends to the interface and passes through the interface up to inter-distance $(\mathrm{d}=0.1 \mu \mathrm{m})$, beyond a size the crack propagates in the particle is in pure mode I. The propagation kinetics is all the stronger as the composite is elaborate at high temperatures the stress intensity factor is all the more important, as the temperature is high. The factor intensity of stress parameter evenly distributed over the two crack fronts. Indeed, the values of the factors resulting from these two points are identical and what is the temperature. The results shown in this figure show that internal stresses promote crack instability in Mode II (Fig. 5.b).

Fig. 5.c shows the effect of temperature on the Mode III stress intensity factor resulting from the two cracking fronts. This figure clearly shows that an increase in the working temperature leads to an intensification of this fracture criterion. We noted however that the residual stresses favor the crack development in mode III. The values of this factor obtained in this case are much more significant. This clearly illustrates that such a crack propagates in mode II and III shear mode and essentially in mode III. Mechanical energy is repartee fairly in points A and B of the cracking defect.
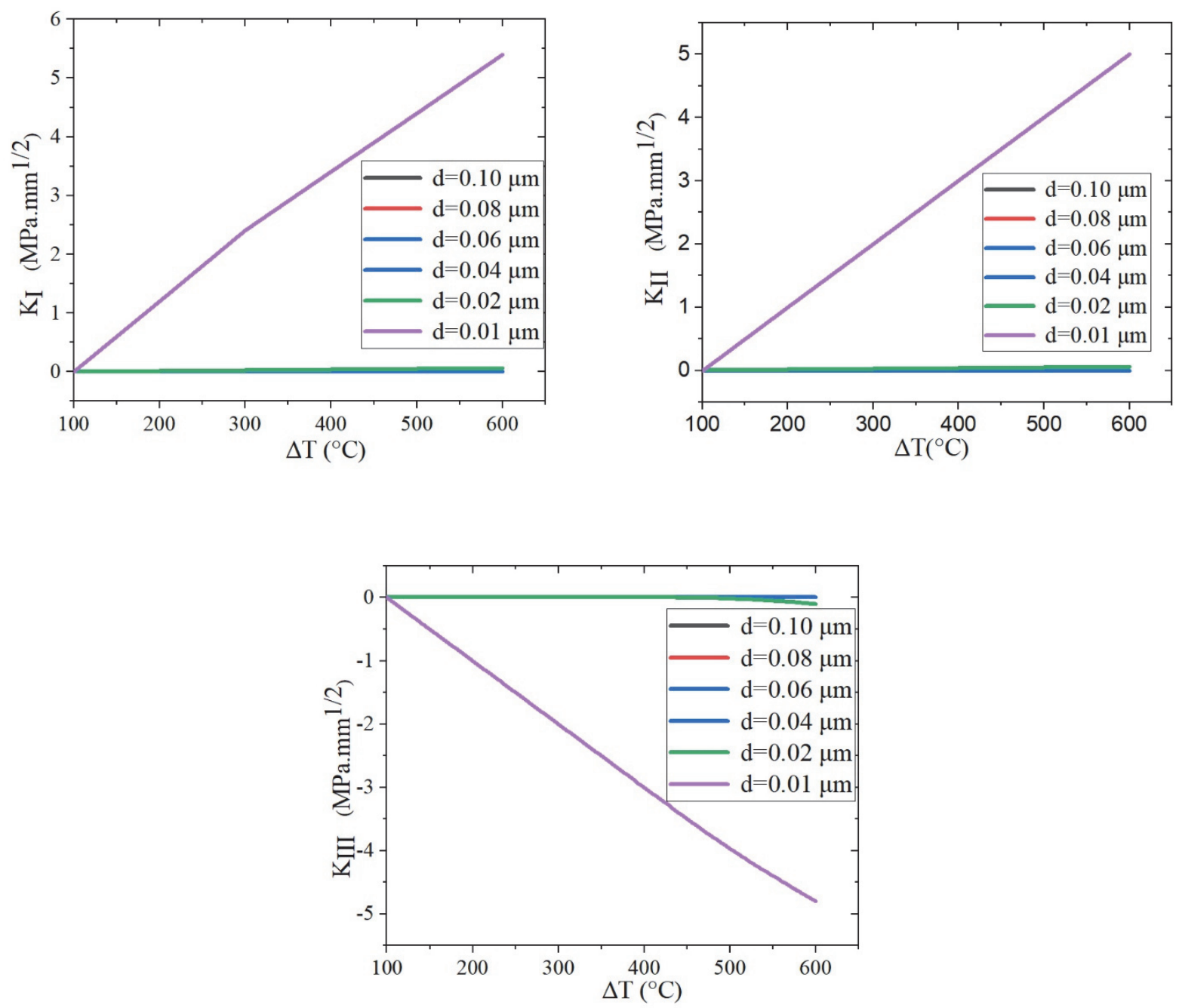

Figure 5: Variation of the stress intensity factors in mode (I, II, III) as a function width of the crack 


\section{CONCLUSION}

his work, focused on the analysis of the thermomechanical behaviour of a composite cubic cell with a metal matrix, is part of a very current scientific and technological context.

$\checkmark \checkmark$ It should be noted that the maximum stresses in particle are at the bottom while those of the matrix are near at the bottom; this is mainly due to the interaction effect and difference of the mechanical properties of the materials. For a zero inter-distance, the increase in temperature gradient elicit the transformation of residual tensile stresses to residual compressive stresses.

$\checkmark$ With regard to the $S_{11 \max }$ and $S_{22 \max }$ constraints, we note that the matrix supports the greatest load of these constraints. The stresses $S_{11 \text { max }}$ are three times significant in the matrix than particle. Reverse behaviour occurs for the $S_{22 \max }$ and $S_{33 \max }$ stresses, they are maximum in particle. The increase in temperature gradient decreases the stresses.

$\checkmark \quad$ It should also be noted that the effect of the inter-distance is significant for the low values of "d" and less than 0.4 $\mu \mathrm{m}$ for the two cases namely on the interface of the matrix and on the external area of the particle.

$\checkmark$ The growth of a crack initiated in the composite matrix Al/Sic perpendicular to the interface favours its instability very strongly. Growth kinetics grow very rapidly as the crack tends towards the interface

$\checkmark$ For maximum residual stress at $\mathrm{d}=0.1 \mu \mathrm{m}$ and $\Delta \mathrm{T}=600^{\circ} \mathrm{C}$. The difference in thermal expansion coefficient shows that the crack is more unstable in three modes, and that the stress intensity factor values increase when the crack size crosses the interface at the inter-distance $(\mathrm{d}=0.1 \mu \mathrm{m})$ for all three modes.

\section{REFERENCES}

[1] Zaoui, B., Baghdadi M., Serier B., Belhaouari M. (2020). Finite element analysis of the thermomechanical behavior of metal matrix composites (MMC). Frattura ed Integrità Strutturale, 51, pp. 174-188; DOI: 10.3221/IGF-ESIS.51.14.

[2] Aicha, M., Madani K., Abdelkader L. (2018). Effect of crack position and size of particle on SIF in SiC particles reinforced Al composite. Frattura ed Integrità Strutturale, 48, pp. 152-160. DOI: 10.3221/IGF-ESIS.48.18.

[3] Metehri, A., Serier, B., Bachir Bouiadjra, B., Belhouari, M. and Mecirdi M.A.(2009). Numerical analysis of the residual stresses in polymer matrix composites. Materials and Design Journal, 30, pp. 2332-2338. DOI: $10.1016 /$ j.matdes.2008.11.009.

[4] Hashin, Z., Shmuel, S., (1963). A variational approach to the theory of the elastic behaviour of multiphase materials. Journal of the Mechanics and Physics of Solids, 11(2), pp. 127-140; DOI:10.1016/0022-5096(63)90060-7.

[5] Simulia, Dassault Systems. Abaqus software. Version 6.11. (2011)

[6] Sellam, S., Serier, B., Bouafia, F., Bachir Bouidjra, B. and Sardar, S. H. (2013). Analysis of the stresses intensity factor in alumina-Pyrex composites. Journal Computational Materials Science, 72, pp. 68-80.

DOI: $10.1016 /$ j.commatsci.2013.01.030.

[7] Nehari, T., (2018). Numerical Study of Residual Thermal Stresses in MMC. Mechanics and Mechanical Engineering 22(4), pp. 1099-1109.

[8] Mecirdi, M.A., Serier B. (2015). Calcul des facteurs d'intensité de contraintes (FIC) pour les fissures interfaciales dans les composites fibreux. Revue des composites et des matériaux avancés, 25, pp.311-325.

[9] Victor, N. K., Emilios, S., John, V., Chrysoula, R. (2019). A SEM-X-Ray assisted experimental approach for the determination of mechanical and thermal load - induced damage in MMCs. Frattura ed Integrità Strutturale, 50, pp. 414-422. DOI: 10.3221/IGF-ESIS.50.35.

[10] Hadj, B. R, Boutabout B. (2020). Three-dimensional numerical analysis of a joint bonded reinforced with silica nanoparticles (SiO2). Frattura ed Integrità Strutturale, 52, pp. 128-136. DOI: 10.3221/IGF-ESIS.52.11.

[11] Hu, G K. and Weng G J. (1998). Influence of thermal residual stresses on the composite macroscopic behavior, Mechanics of Materials, 27, pp. 229-240. DOI: 10.1016/S0167-6636(97)00050-1.

[12] Ouinas, D., Bachir Bouiadjra B., Benderdouche N. (2008). Interaction effect of a main crack emanating from a semicircular notch and a microcrack, Comput. Mater. Sci. 43, pp. 1155-1159; DOI: 10.1016/j.commatsci.2008.03.014.

[13] Ouinas, D., Bachir Bouiadjra B., Benderdouche N., Ait Saadi B., Vina J. (2011). Numerical modelling of the interaction macro-multimicrocracks in a plate under tensile stress' Journal of Computational Science, 2, pp. 153-164. DOI: $10.1016 /$ j.jocs.2010.12.009.

[14] Bouafia, F., Serier B., Bachir Bouiadjra B. (2012). Finite element analysis of the thermal residual stresses of SiC particle reinforced aluminum composite, Computational Materials Science, 54, pp. 195-203.

DOI:10.1016/j.commatsci.2011.10.030. 